\title{
Favourable and Unfavourable Effect of Homogeneous Static Magnetic Field on Germination of Zea mays L. (Maize) Seeds
}

\author{
J. Torres ${ }^{1}$, J. Aranzazu-Osorio ${ }^{1} \&$ E. Restrepo-Parra ${ }^{2}$ \\ ${ }^{1}$ Research Group on Electromagnetic Fields, Environment and Public Health, Physics Department, Universidad \\ de Caldas, Manizales, Colombia \\ ${ }^{2}$ Departamento de Física y Química, Universidad Nacional de Colombia, Caldas, Manizales, Colombia \\ Correspondence: J. Torres, Departamento de Física, Universidad de Caldas, Caldas, Manizales, Colombia. Tel: \\ 57-6-8781514. E-mail: javier.torres@ucaldas.edu.co
}

Received: September 7, 2018

Accepted: November 11, 2018

Online Published: January 15, 2019

doi:10.5539/jas.v11n2p90

URL: https://doi.org/10.5539/jas.v11n2p90

\begin{abstract}
The effect of homogeneous static magnetic stimulation on Zea mays L. (maize) seeds and its potential utility as a tool in biotechnological development for the improvement of maize seeds was studied. The values of magnetic flux density that influenced the biological development of some plant species of the Poaceae family were determined from a literature review. ICA V-305 variety corn seeds were exposed to seven values of magnetic flux density between $50.0 \mathrm{mT}$ and $250.0 \mathrm{mT}$, with homogeneity of $98.4 \%$ and at $(1.0,3.0,5.0$ and 7.0$) \mathrm{min}$ exposure times. The mean germination time (MGT), index of germination speed $\left(V_{G e r}\right)$ and germination rate $\left(G_{\max }\right)$ were evaluated as responses. The magnetic flux density of $50.0 \mathrm{mT}$ with a one-minute exposure time recorded the largest reduction (12.4\%) in the MGT while the germination rate for the same treatment increased by $17.4 \%$ with respect to the control. No significant effects of the magnetic treatment were recorded for the $G_{m a ́ x}$. The magnetic treatment of seeds with homogeneous static fields does not have as favourable a response as the treatments with fields with magnetic gradients, that is to say, using toroidal magnets.
\end{abstract}

Keywords: magnetic flux density, magnetic field gradient, germination rate, average germination time, seed magnetic treatment

\section{Introduction}

Advances in the knowledge of the evolution of living beings under the presence of the geomagnetic field has generated interest in the study of magnetosensitivity of various organisms. Regarding plants, Belyavskaya presents an interesting review on the effect of the geomagnetic field in the biochemistry, physiology and biology of plants (Belyavskaya, 2004). Although there is a large number of reports, mainly in the area of agriculture, which indicate that plant systems respond when treated with magnetic field (Galland \& Pazur, 2005; Maffei, 2014; Pietruszewski \& Martinez, 2015; Teixeira da Silva \& Dobránszki, 2015; De Sousa et al., 2016), magnetic stimulation of plant systems can be considered as a technique still in the research stage. In this sense, works can be found with barley, wheat, and oats, among others, and for maize seeds, effects are reported which are presented in Table 1. Seeds have gone through magnetic fields with values from microtesla to hundreds of millitesla, although there are studies of the response to stimuli in units of tesla. For this purpose, passive magnetic sources (permanent magnets) or active sources have been used: Helmholtz coils, electromagnets and/or solenoids (Table 1), in which the values of $B$, selected by the experimenters, and the values that generated favourable responses $\left(B_{f a v}\right)$ in the study variables are also recorded.

The results reported raise several levels of discussion, of which two can be taken into consideration. The first level corresponds to the need to determine which of the physical factors are determinant in this technique and how they should be controlled during exposure. Taking into account what was stated before, it is established that the biological effect of magnetic fields is dependent on factors such as the polarity of the field and the value of $B$ it generates (Van, Teixeira da Silva, Ham, \& Tanaka, 2011). Nevertheless, it is notorious that in the methodology of exposure reports selected in Table 1, few of them presented the values of homogeneity or gradient of the magnetic field. 
The second level is aimed at identifying and explaining the cause of the biological effects observed from the processes activated at the biophysical and biochemical level, since the interpretation of these affectations can be contributed to the understanding of the mechanisms that are unchained in the plant under the effect of the magnetic treatment. The literature reports influence on enzymatic activation, imbibition (Vashisth \& Nagarajan, 2010; Shine, Guruprasad, \& Anand, 2011), enhanced reactive oxygen species content (Shine et al., 2017), variations in ionic currents (Socorro \& García, 2012), modifications in water adsorption processes (Torres, Socorro, \& Hincapie, 2018) and changes in the cellular membrane characteristics and RNA quantification (Goodman, Greenebaum, \& Marron, 1995).

For all the above mentioned reasons, the effect of homogeneous and intense static magnetic flux density on the germination of maize seeds are studied in the present work, unifying criteria that have been proposed in Valberg (1995), Kaune (1995), and Lee (1996) reports, where studies regarding to the physical variables involved through characterization of the magnetic field sources used in the experiments are presented.

\section{Materials and Methods}

\subsection{Plant Material}

Commercial Maize seeds (Zea mays L. cv. ICAV305, Semillas del Pacífico, Cartago, Colombia), fit between 1.000 and 2.000 MASL were used. The seeds without visible damage and with uniform morphology were pre-selected prior to the magnetic treatment. The preselected seeds were first sieved by passing them through a $(8.0 \times 8.0) \mathrm{mm}$ mesh sieve, and later sieved using a $(6.0 \times 6.0) \mathrm{mm}$ mesh sieve to homogenize the sample size separating seeds into large, medium and small sizes in order to use the medium size seeds which have $0.3878 \pm 0.0002 \mathrm{~g}$ average mass and $0.356 \pm 0.008 \mathrm{~cm}^{3}$ average volume.

Table 1. Maize seeds magnetic treatment experiments characteristics. N.I, no information

\begin{tabular}{|c|c|c|c|c|c|c|c|}
\hline Variety & $\begin{array}{l}B_{f a v} \\
(\mathrm{mT})\end{array}$ & $\begin{array}{l}f \\
(\mathrm{~Hz})\end{array}$ & $t_{\exp }(\min )$ & Source & $B$ Variation (\%) & Improvement & Reference \\
\hline CL-11, CL-12 & 160,560 & 0 & 30,60 & Coil & N.I. & In germination processes & Dominguez, et al., 2010 \\
\hline N.I. & 150 & 0 & 10 & N.I & N.I. & $\begin{array}{l}\text { In germination processes and } \\
\text { establishment of seedling }\end{array}$ & Aladjadjiyan, 2002 \\
\hline N.I. & 50 & 0 & Continuous & Magnet & N.I. & In the first ontogenetic states & Rácuciu \& Creanga, 2006 \\
\hline Ramda & 125,250 & 0 & $1,10,20,60,1.440$ & Magnet & N.I. & $\begin{array}{l}\text { In germination processes and } \\
\text { establishment of seedling }\end{array}$ & $\begin{array}{l}\text { Florez, Carbonell, \& } \\
\text { Martínez, } 2007\end{array}$ \\
\hline Ganga Safed-2 & 100,200 & 0 & 60,120 & Electromagnet & $\begin{array}{l}0.6 \% \text { horizontal axis, } \\
1.6 \% \text { vertical axis }\end{array}$ & $\begin{array}{l}\text { In germination processes, } \\
\text { root characteristics and } \\
\text { establishment of seedling }\end{array}$ & Vashisth \& Nagarajan, 2008 \\
\hline Ganga Safed-2 & 100,200 & 0 & 60,120 & Electromagnet & $\begin{array}{l}0.6 \% \text { horizontal axis, } \\
1.6 \% \text { vertical axis }\end{array}$ & In the viability of stored seeds & Vashisth \& Nagarajan, 2009 \\
\hline Ganga Safed-2 & 100,200 & 0 & 60 & Electromagnet & $\begin{array}{l}0.6 \% \text { horizontal axis, } \\
1.6 \% \text { vertical axis }\end{array}$ & $\begin{array}{l}\text { In germination processes and } \\
\text { vigour of seedlings, improvement } \\
\text { in water absorption in phases II } \\
\text { and II of germination }\end{array}$ & Vashisth \& Nagarajan, 2010 \\
\hline HQPM-1 & 200 & 0 & 60 & Electromagnet & $\begin{array}{l}0.8 \% \text { horizontal axis, } \\
1.5 \% \text { vertical axis }\end{array}$ & $\begin{array}{l}\text { In seedling characteristics } \\
\text { and chlorophyll content }\end{array}$ & Vashisth \& Joshi, 2016 \\
\hline $\begin{array}{l}\text { San Jeronimo, } \\
\text { San Jose, San Juan }\end{array}$ & 480 & 0 & $3,6,9,112,15$ & Solenoid & N.I. & $\begin{array}{l}\text { In the establishment } \\
\text { of the seedlings }\end{array}$ & Zepeda et al., 2010 \\
\hline AS722, HS2, CAZ & 480 & 0 & $5,10,15$ & Solenoid & N.I. & $\begin{array}{l}\text { Changes in the characteristics } \\
\text { of exposed seed }\end{array}$ & Zepeda et al., 2011 \\
\hline San Jose & 4 & 0 & 3 & Solenoid & N.I. & $\begin{array}{l}\text { In the establishment } \\
\text { of the seedlings }\end{array}$ & $\begin{array}{l}\text { Isaac, Hernández, } \\
\text { Domínguez, \& Cruz, } 2011\end{array}$ \\
\hline $\begin{array}{l}\text { CL-11, CL-12, CL-13, } \\
\text { CL-1, CL-4 }\end{array}$ & 60 & 60 & 7.5 & Electromagnet & N.I. & $\begin{array}{l}\text { In the vigour of the plant. } \\
\text { The response depends } \\
\text { on the genotype of the seed }\end{array}$ & Hernandez et al., 2009 \\
\hline HQPM.1 & 100,200 & 0 & 60,120 & Electromagnet & $\begin{array}{l}0.6 \% \text { horizontal axis, } \\
1.6 \% \text { vertical axis }\end{array}$ & In germination processes & $\begin{array}{l}\text { Shine, Kataria, Guruprasad, } \\
\text { \& Anand, } 2017\end{array}$ \\
\hline N.I & 10 & 50 & 60 & Helmholtz & N.I. & Mitotic index increase & Rácuciu, 2011 \\
\hline
\end{tabular}




\subsection{Magnetic Stimulation}

The generation of the magnetic field was conducted with a GMW electromagnet with $7.0 \mathrm{~cm}$ diameter circular cores, and a $4.0 \mathrm{~cm}$ spacing between them, with an operating range between 0 and $1.300 \mathrm{mT}$ (Figure 1a), fed with an N5768A Agilent Technologies ${ }^{\circledR}$ direct current (DC) source. $B$ measurements were performed with an FW Bell 5180 teslameter with transverse probe and $0.01 \mathrm{mT}$ resolution in ranges up to $30.00 \mathrm{mT}$, and $0.1 \mathrm{mT}$ for ranges up to 3,000.0 $\mathrm{mT}$. The spatial characterization of the electromagnet allowed defining the distribution of $B$ and thus to relating the volume of the cylindrical container used to place the seeds with the homogeneity value of $B\left(h_{B}\right)$. The volume of the cylindrical container for 25 maize seeds is $12.3 \mathrm{~cm}^{3}$ which corresponds to $h_{B}$ of $98.4 \%$. The box in Figure 1b represents a cross-section of the yellow cylinder in Figure 1a, whose axis is collinear with that of the cores. The uniformity of the magnetic parameters $h_{B}$ and $B$ in the seeds exposure of the complete experiment is guaranteed by the design and elaboration of a support that positions the cylindrical container (Figure 1a) and with the use of a high stability current source. In addition, the temperature in the electromagnet coils and the seeds being exposed was monitored thus ensuring that it was not higher than $2.0{ }^{\circ} \mathrm{C}$ above room temperature.

Magnetic stimulation was performed for 29 doses (D) plus control, exposing seeds to values between $50.0 \mathrm{mT}$ and $250.0 \mathrm{mT}$ and exposure times $\left(t_{\text {exp }}\right)$ of $(1.0,3.0,5.0$ and 7.0) $\mathrm{min}$ (Table 2). Four replications for each treatment were developed.

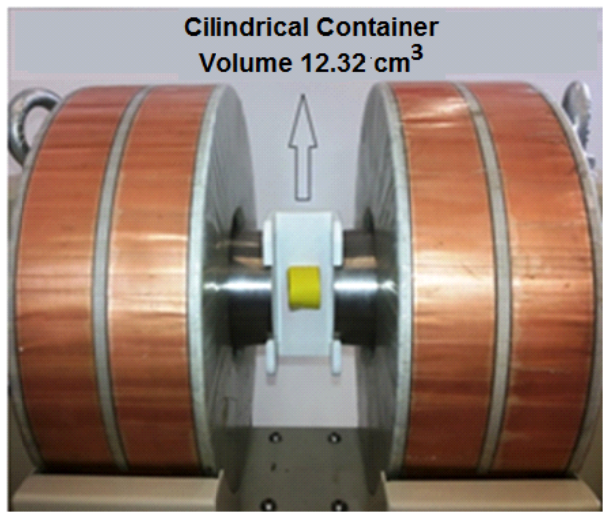

a

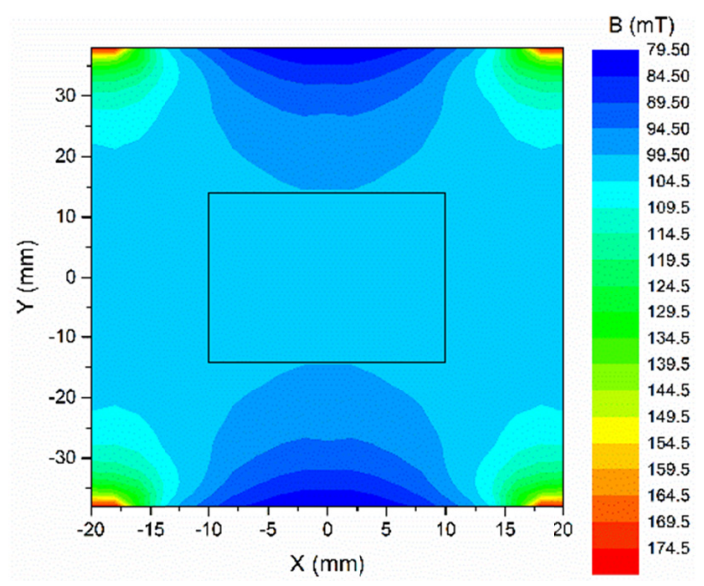

$\mathrm{b}$

Figure 1. (a) System for magnetic stimulation; (b) Graph of the characterization of $B$, in $\mathrm{z}=0$, with $40.0 \mathrm{~mm}$ separation between the cores of the electromagnet, operating with a nominal $B$ of $100.0 \mathrm{mT}$

Table 2. Values of magnetic stimulation doses relating the magnetic flux density and the time of exposure

\begin{tabular}{lllll}
\hline \multirow{2}{*}{$(\mathbf{m T})$} & \multicolumn{4}{c}{$\boldsymbol{t}_{\boldsymbol{e x p}}(\mathbf{m i n})$} \\
\cline { 2 - 5 } & $\mathbf{1 . 0}$ & $\mathbf{3 . 0}$ & $\mathbf{5 . 0}$ & $\mathbf{7 . 0}$ \\
\hline 50.0 & D11 & D21 & D31 & D41 \\
100.0 & D12 & D22 & D32 & D42 \\
120.0 & D13 & D23 & D33 & D43 \\
150.0 & D14 & D24 & D34 & D44 \\
160.0 & D15 & D25 & D35 & D45 \\
200.0 & D16 & D26 & D36 & D46 \\
250.0 & D17 & D27 & D37 & D47 \\
\hline
\end{tabular}

\subsection{Sowing}

Sowing was done as established by the International Seed Testing Association (ISTA). The parameters of temperature $(\mathrm{T})$ and volume of water $\left(\mathrm{V}_{\mathrm{H}_{2} \mathrm{O}}\right)$ were determined in a previous germination test in which $\mathrm{V}_{\mathrm{H}_{2} \mathrm{O}}$ responses of $\left(8.0,12.0,16.0\right.$ and 20.0) $\mathrm{ml}$ and $\mathrm{T}$ of $(24.0,27.0$ and 30.0$){ }^{\circ} \mathrm{C}$ (data not shown) were evaluated. The best response was obtained with $12.0 \mathrm{ml} \mathrm{mL}$ of $\mathrm{V}_{\mathrm{H} 2 \mathrm{O}}$ and $30.0^{\circ} \mathrm{C}$. 
After receiving the magnetic treatment, the seeds were planted in $(100 \times 15) \mathrm{mm}$ Petri dishes with absorbent paper moistened with $12.0 \mathrm{ml}$ of distilled water as germination matrix. The seeds were kept in an Incucell 2221 incubator without light. The incubation temperature was $30.10 \pm 0.14{ }^{\circ} \mathrm{C}$ and the humidity inside the incubator was $59.0 \pm 3.39 \%$.

Additionally, a characterisation of the magnetic flux density inside the incubator was conducted every $5.0 \mathrm{~cm}$ for the vertical and horizontal directions. Resulting values were obtained in a range between a $B_{\min }=0.02 \mathrm{mT}$ and a $B_{\max }=0.14 \mathrm{mT}$ from these measurements and a particularly high $B$ generated by a magnet that triggers the closure of the internal door of the incubator $B_{P}=4.19 \mathrm{mT}$.

The distribution of the Petri dishes in the incubator was randomly defined, ensuring that plates were not positioned within $10.0 \mathrm{~cm}$ of the magnet located in the internal door of the incubator (Figure 2). This procedure is required since there are reports that present responses with significant differences, depending on the variables employed for magnetically treated seeds. For instance, in the case of DC, values close to $4.0 \mathrm{mT}$ have been reported in Cakmak, Dumlupinar, and Erdal (2010), and Majd, Shabrangi, Bahar, and Abdi (2009).

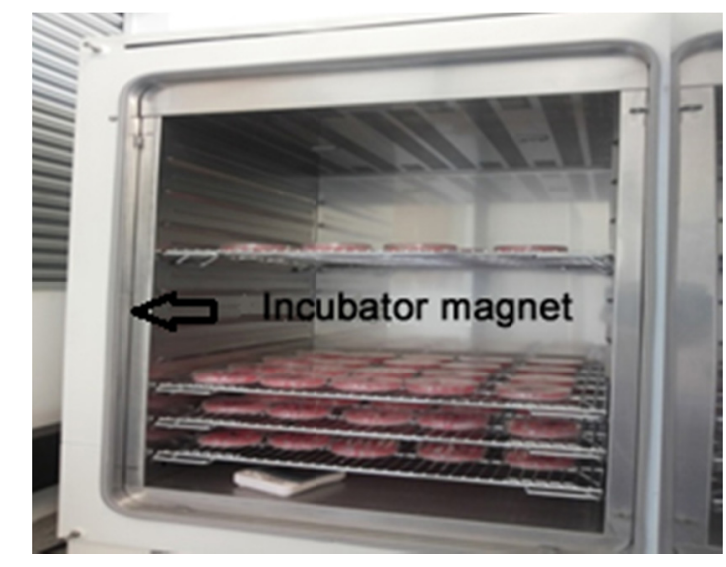

Figure 2. Image of seed sowing system

\subsection{Germination Tests}

Germination was reviewed 16 hours after sowing every four hours until the 68th hour. Corn seeds are assumed to germinate when the radicle reaches a length equal to or greater than $1 \mathrm{~mm}$ (Florez, Carbonell, \& Martínez, 2007).

In order to evaluate the effect of the treatments on germination, the mean germination time (MGT) (Equation 1) according to the formula of (Maguire, 1962), and the rate or percentage of germination $\left(G_{\max }\right)$ was evaluated.

$$
\begin{aligned}
M G T & =\frac{\sum_{i=1}^{n} N_{i} \times t_{i}}{\sum_{i=1}^{n} N i} \\
V_{G e r} & =\sum_{i=1}^{n} \frac{N i}{t i}
\end{aligned}
$$

Where, $N i$ is the number of seeds germinated in the $i^{\text {th }}$ time; $t i$ is the $i^{\text {th }}$ time elapsed.

\subsection{Data Analysis}

The choice of the statistical test for the analysis of the MGT, $V_{G e r}$ and $G_{\max }$ was made with the evaluation of two completely randomized design assumptions: normal distribution of errors (Shapiro-Wilks) and homoscedasticity (Bartlett). Given the parametric nature of the data, a one-way ANOVA test was used with the R program. Pairwise comparisons were performed using the Least Significant Difference (LSD) test.

\section{Results and Discussion}

For V-305 ICA maize seeds variety, the data obtained from the effect of the treatment with homogeneous static magnetic field on the germinative development behaviour show an effect on MGT and $V_{G e r}$ that has favourable and unfavourable effects. Five doses that had significant differences with the control for MGT are presented in Figure 5 and in Table 3. Doses D11, D26, D32, D37 and D44 presented statistical differences for MGT in 
relation to the control (Table 3). With D11 a reduction of $12.4 \%$ (3.4 h) was obtained, whereas with D37, D32, D26, D44 significant increase between $5.2 \%(1.4 \mathrm{~h})$ and $12.0 \%(3.3 \mathrm{~h})$ was observed.

Table 3. MGT of the magnetic treatments studied

\begin{tabular}{llllllll}
\hline Treatment & MGT & Treatment & MGT & Treatment & MGT & Treatment & MGT \\
\hline Control & $27.386 \pm 0.979$ & & & & & & \\
\hline D11 & $23.997 \pm 1.510^{* * * *}$ & D21 & $27.033 \pm 2.131$ & D31 & $28.084 \pm 1.198$ & D41 & $26.606 \pm 0.296$ \\
D12 & $26.771 \pm 0.615$ & D22 & $26.659 \pm 1.309$ & D32 & $29.748 \pm 1.743 * * *$ & D42 & $26.379 \pm 0.964$ \\
D13 & $26.933 \pm 1.166$ & D23 & $28.688 \pm 2.028$ & D33 & $26.901 \pm 1.838$ & D43 & $27.875 \pm 2.850$ \\
D14 & $26.860 \pm 1.868$ & D24 & $27.536 \pm 1.436$ & D34 & $26.933 \pm 1.064$ & D44 & $28.800 \pm 1.492^{*}$ \\
D15 & $26.737 \pm 0.750$ & D25 & $26.441 \pm 0.904$ & D35 & $28.657 \pm 2.238$ & D45 & $26.841 \pm 1.963$ \\
D16 & $28.282 \pm 0.942$ & D26 & $28.875 \pm 1.252^{*}$ & D36 & $26.203 \pm 0.909$ & D46 & $27.431 \pm 0.930$ \\
D17 & $27.189 \pm 1.944$ & D27 & $26.873 \pm 1.341$ & D37 & $30.660 \pm 1.397 * * *$ & D47 & $26.767 \pm 2.271$ \\
\hline
\end{tabular}

Note. The table shows the average value and the standard deviation for each of the treatments. The asterisk indicates differences with the control: $* * * *(\mathrm{P}<0.001)$ very strongly significant, $* * *(0.001<\mathrm{P}<0.01)$ strongly significant, $* *(0.01<\mathrm{P}<0.05)$ significant and $*(0.05<\mathrm{P}<0.1)$ differences.

The results for $V_{G e r}$ present a similar behaviour as shown in Table 4 and in Figure 6 . The treatments D11, D23, D26, D31, D32, D35, and D37 registered significant differences with the control (Table 4), and D11 showed an increase of this index of speed of $17.4 \%(0.16 \mathrm{seeds} / \mathrm{h})$. In contrast, doses D37, D31, D32, D26, D35 and D23 had a decrease between $7.3 \%(0.07$ seeds $/ \mathrm{h})$ and $16.1 \%(0.14 \mathrm{seeds} / \mathrm{h})$.

It was not possible to establish significant differences for the germination rate, but it must be made clear that the control seeds showed a germination rate of $91.0 \%$, which was reached by the seeds that received the magnetic treatments.

In analysing these results, it is important to highlight two distinctive features: first, the number of treatments with unfavourable results (five) was higher for the variables $V_{G e r}$ and MGT, which presented statistical differences between significant and highly significant (Tables 3 and 4). The second shows that for exposure with homogeneous static magnetic field, low dose treatments improve germination and high dose treatments decrease germination in MGT and $V_{G e r}$.

Table 4. Speed of germination of the studied magnetic treatments

\begin{tabular}{|c|c|c|c|c|c|c|c|}
\hline Treatment & $V_{G e r}(\mathrm{sem} / \mathrm{h})$ & Treatment & $V_{\text {Ger }}(\mathrm{sem} / \mathrm{h})$ & Treatment & $V_{G e r}(\mathrm{sem} / \mathrm{h})$ & Treatment & $V_{\text {Ger }}(\mathrm{sem} / \mathrm{h})$ \\
\hline Control & $0.895 \pm 0.058$ & & & & & & \\
\hline D11 & $1.051 \pm 0.059 * * * *$ & $\mathrm{D} 21$ & $0.914 \pm 0.027$ & D31 & $0.793 \pm 0.074 * * *$ & $\mathrm{D} 41$ & $0.941 \pm 0.052$ \\
\hline D12 & $0.884 \pm 0.072$ & D22 & $0.869 \pm 0.111$ & D32 & $0.795 \pm 0.060 * * *$ & D42 & $0.940 \pm 0.073$ \\
\hline D13 & $0.907 \pm 0.071$ & $\mathrm{D} 23$ & $0.830 \pm 0.051^{*}$ & D33 & $0.895 \pm 0.068$ & D43 & $0.917 \pm 0,054$ \\
\hline D14 & $0.913 \pm 0.064$ & D24 & $0.838 \pm 0.072$ & D34 & $0.884 \pm 0.078$ & D44 & $0.953 \pm 0.089$ \\
\hline D15 & $0.926 \pm 0.039$ & D25 & $0.883 \pm 0.130$ & D35 & $0.818 \pm 0.014 * *$ & D45 & $0.928 \pm 0.060$ \\
\hline D16 & $0.950 \pm 0.070$ & D26 & $0.809 \pm 0.077 * *$ & D36 & $0.884 \pm 0.034$ & D46 & $0.909 \pm 0.032$ \\
\hline D17 & $0.888 \pm 0.066$ & D27 & $0.935 \pm 0.031$ & D37 & $0.751 \pm 0.106^{* * * *}$ & D47 & $0.907 \pm 0.110$ \\
\hline
\end{tabular}

Note. The table shows the average value and the standard deviation for each of the treatments. The asterisk indicates differences with the control: $* * * *(\mathrm{P}<0.001)$ very strongly significant, $* * *(0.001<\mathrm{P}<0.01)$ strongly significant, $* *(0.01<\mathrm{P}<0.05)$ significant and $*(0.05<\mathrm{P}<0.1)$ differences.

When analysing these results, the positive and negative behaviour suggests that the characteristics of the magnetic fields, such as homogeneity or gradients, are probably influencing alterations in metabolism and/or the transport of phytohormones involved in the germination process. This can be interpreted as if the effect of the homogeneous and intense static magnetic field has a low positive response on the germinative processes in maize seeds. 
On the other hand, seeking to contrast this behaviour with others obtained with magnetically treated maize, in the literature it is found that this type of seed has been studied in different varieties for which there was an increase in response to the attack of a pathogen, when the seeds were treated with a electromagnetic field at 60 (Zepeda et al., 2014) length and mass of the root and plant (Aladjadjiyan, 2002; Vashisth \& Nagarajan, 2009), vigour indexes (Kataria, Baghel, \& Guruprasad, 2015; Vashisth \& Nagarajan, 2009; Isaac, Hernández, Domínguez \& Cruz, 2011) and establishment (Zepeda et al., 2010). Variables that express effects on germination improvement are reported in: $G_{\max }$ between $10 \%$ and $16 \%$ (Hernandez et al., 2009; Dominguez et al., 2010; Zepeda et al., 2011; Isaac, Hernández, Domínguez,, \& Cruz, 2011); $V_{G e r}$ (Dominguez et al., 2010; Shine et al., 2017; Zepeda et al., 2010); MGT and the time to germinate $10 \%, 25 \%$, and $75 \%$ of the seeds have presented significant decrease up to $21 \%$ for the MGT (Florez, Carbonell, \& Martínez, 2007; Martinez, Florez, \& Carbonell, 2017) regarding the control.

However, by reviewing each of the references presented in detail and identifying the magnetic source and the factors related to the characteristics of the magnetic field with which the exposure was conducted, it was found that for works mentioned in Table 1 sources that show magnetic fields with spatial characteristics and parameters different between them and different from those used in this experiment have been used. In addition, in the methodology of exposure few presented homogeneity values or gradients.

Therefore, in order to compare the results of this work with those mentioned above, not only the value of $B$ should be taken into consideration. The first step is to identify the type of source, whether a passive (magnets) or active source (coils, electromagnet or solenoid) were used, and if magnets were used, identify if they were toroidal or cylindrical or square bar magnets. Given that it must be clear that there is always some degree of heterogeneity in the spatial distribution of the magnetic field, which, when categorized in percentage terms from highest to lowest, appears with higher percentage in toroidal magnets, followed by cylindrical rods, solenoids, electromagnets and in much lower percentage in Helmholtz coils. For example, when comparing the images presented in Figure $1 \mathrm{~b}$ and Figure 4, it can be observed that there is a magnetic field with high homogeneity in the electromagnet, while in toroidal magnets magnetic gradient values are very high besides a variation in the polarity can be observed, which suggests very different experiments (Torres, Hincapie, \& Gilart, 2018). But, in order to have a high homogeneity value in the electromagnet, the samples must be positioned in the central zone between the cores since, otherwise, this value decreases drastically.

If the magnetic source was active, it is necessary to determine whether it was fed by DC or AC, since the energy density of a magnetic field $\mathrm{AC}\left(\rho_{A C}\right)$ is twice that of DC $\left(\rho_{D C}\right)$-Equations 3 and 4 -as well as to consider the exposure doses (D) which result from operating the field energy density with exposure time $\left(t_{\text {exp }}\right)$-Equation 5-as discussed in (Pietruszewski \& Martinez, 2015).

$$
\begin{gathered}
\rho_{A C}=\frac{B^{2}}{\mu_{0}} \\
\rho_{D C}=\frac{B^{2}}{2 \mu_{0}} \\
D=\rho t_{\exp }
\end{gathered}
$$

Thus, when comparing the results of this study with those of previous reports, care should be taken with the interpretation of the results with stimulation in $\mathrm{AC}$ and those of experiments that were done with toroidal magnets. Consequently, when comparing the favourable results of this work with other works, we started by discarding those who worked in AC only leaving reports such as: Isaac et al. (2011), with (2.0, 4.0 and 6.0) mT at $3.0 \mathrm{~min}$ and Zepeda et al. (2011), $480 \mathrm{mT}$ (5.0, 10.0 and 15.0) min, which had exposure with static magnetic field generated with solenoids indicating lower homogeneity values, and the results of Vashisth and Nagarajan (2009) and (2009a), with treatments of $100 \mathrm{mT}$, two hour and $200 \mathrm{mT}$, one hour that used electromagnet, Shine et al. (2017) and Kataria et al. (2015), with similar magnetic flux densities but with higher magnetic field doses than those presented in this work, obtaining similar results to those presented by Flórez et al. (2007), that used toroidal magnets locating the seeds in the walls of the orifice of the toroidal magnet where the values of $B$ change in magnitude, and direction and with a very low homogeneity (Figure 4), the latter having a very good germinative process improvement. 


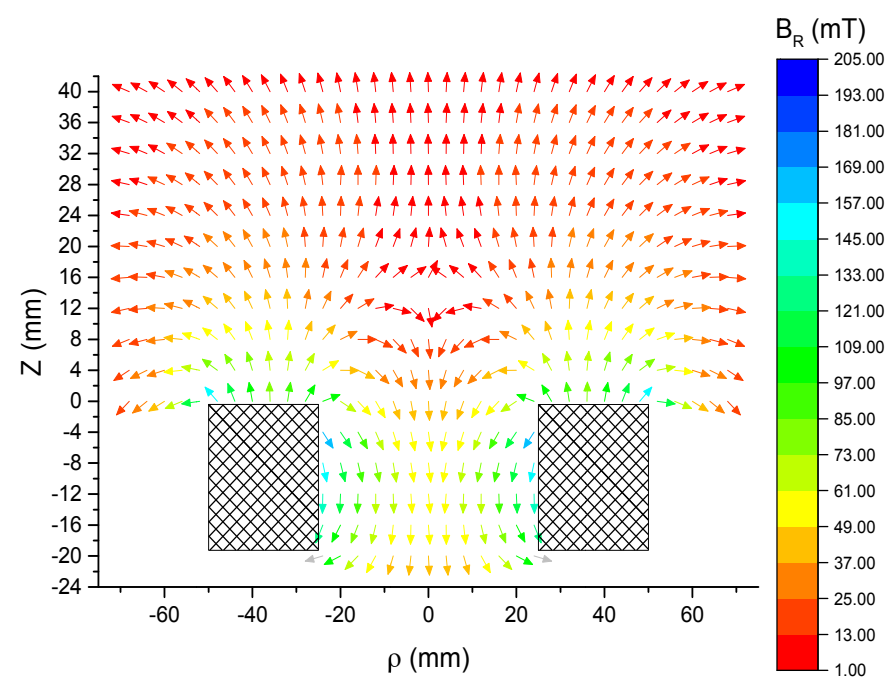

Figure 4. Distribution of the magnetic flux density $(\vec{B})$ for a transverse plane of a toroidal magnet with nominal $B$ $100.0 \mathrm{mT}$, with external radius of $5.00 \mathrm{~cm}$ and internal radius of $2.50 \mathrm{~cm}$

It can be considered that there are several factors of the magnetic field generating favourable and unfavourable effects in the germination. The analysis of this results in the experiment compared to those presented by the mentioned authors, concluded that of exposure to magnetic fields with gradients generated on the germination mechanisms have a better effect than the exposure with homogeneous static fields.

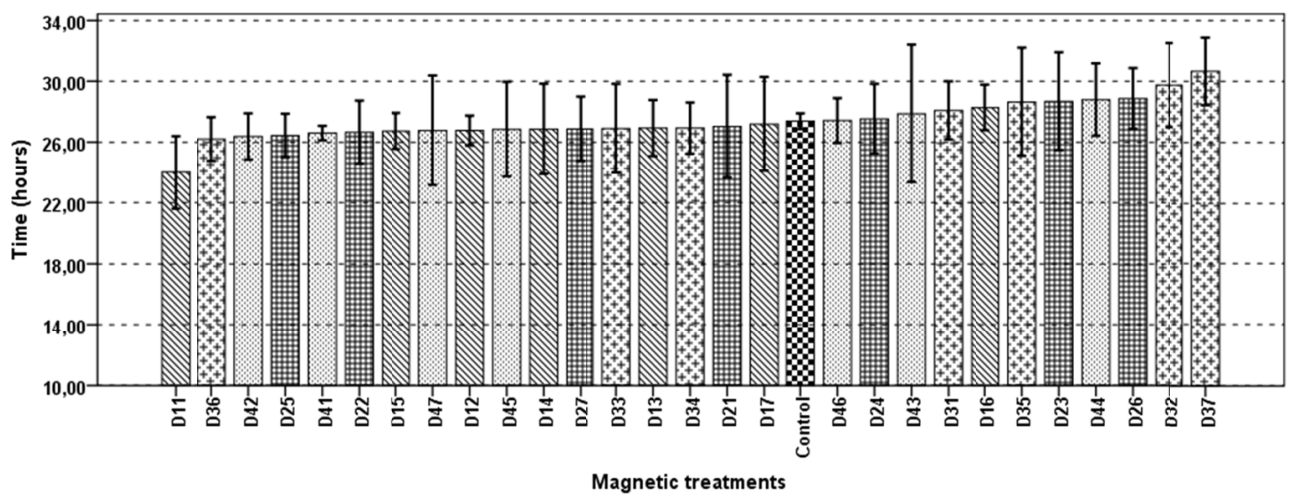

Figure 5. MGT (h) of the evaluated magnetic treatments and control

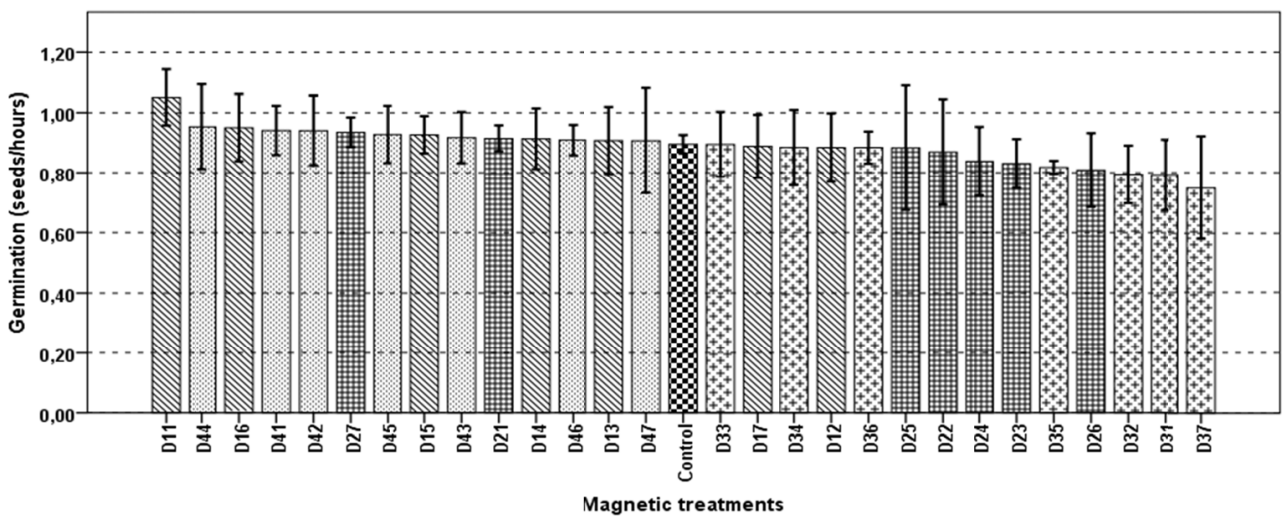

Figure 6. Index of speed of germination of the studied magnetic treatments and control 


\section{Conclusions}

Results presented in this work suggest that the stimulation with homogeneous static magnetic field compromises biological structures and interferes in relevant processes during the germination of Zea mays seeds for the magnetic flux densities and exposure times.

The treatment responses may be affected by different parameters of the magnetic field such as the gradients or the homogeneity of the magnetic flux density produced by the generators. This phenomenon indicates that the treatment with static magnetic field is better when conducted with field gradients, different to the results obtained with homogeneous fields.

Further research with magnetic seed treatment is needed to consolidate a standard procedure that defines the stimulation criteria in such a way as to ensure that the doses involved in the biological processes of the stimulated seeds are secured and that the results are reproducible under established conditions.

In order for the magnetic seed treatment to be profiled as an alternative for their improvement at the agricultural level, a unified application methodology must be developed, which is the result of the verification of which field parameter affects each seed parameter in the seeds and that allows the verification of the results of the investigations in this field and therefore the experimental reproducibility.

\section{References}

Aladjadjiyan, A. (2002). Study of the influence of magnetic field on some biological characteristics of Zea mais. Journal Central European Agriculture, 2, 89-94. https://doi.org/10.5513/jcea.v3i2.118

Belyavskaya, N. (2004). Biological effects due to weak magnetic field on plants. Advance in Space Research, 34, 1566-1574. https://doi.org/10.1016/j.asr.2004.01.021

Cakmak, T., Dumlupinar, \& Erdal, S. (2010). Acceleration of germination and early growth of wheat and bean seedlings grown under various magnetic field and osmotic conditions. Bioelectromagnetics, 1, 1-10.

Carbonell, M., Martinez, E., \& Amaya, J. (2000). Stimulation of germination in rice (Oryza sativa L.) by a static magnetic field. Electro- and Magnetobiology, 19(1), 121-128. https://doi.org/10.1081/JBC-100100303

De Sousa, S., Paparella, S., Dondi, D., Bentivogli, A., Carbonera, D., \& Balestrazzy, A. (2016). Physical Methods for Seed Invigoration: Advantages and Challenges in Seed Technology. Frontiers in Plant Science, 17(646).

Dominguez, A., Hernández, C., Cruz, A., Carballo, A., Zepeda, R., \& Martinez, E. (2010). Semilla de maíz bajo la influencia de irradiación de campos electromagnéticos. Revista Fitotecnia Mexicana, 32(2), 183-188.

Florez, M., Carbonell, M., \& Martínez, E. (2007). Exposure of maize seeds to stationary magnetic fields: Effects on germination and early growth. Environmental and Experimental Botany, 59(1), 68-75. https://doi.org/ 10.1016/j.envexpbot.2005.10.006

Galland, P., \& Pazur, A. (2005). Magnetoreception in plants. J. Plant Res., 371-389. https://doi.org/10.1007/ s10265-005-0246-y

Gholami, A., \& Sharafi, S. (2010). Effect of Magnetic Field on Seed Germination of Two Wheat Cultivars. World Academy of Science, Engineering and Technology, 62, 279-282.

Goodman, E., Greenebaum, B., \& Marron, M. (1995). Effects of electromagnetic fields on molecules and cells. Int Rev Cytol, 158, 279-338. https://doi.org/10.1016/S0074-7696(08)62489-4

Hernandez, C., Dominguez, A., Carballo, A., Cruz, A., Ivanov, R., López, J., \& Valcalcel, J. (2009). Alternating magnetic field irradiation effects on three genotype maize seed field performance. Acta Agrophysica, 14(1), 7-17.

Isaac, E., Hernández, C., D. A., \& Cruz, A. (2011). Effect of pre-sowing electromagnetic treatment on seed germination and seedling growth in maize (Zea mays L.). Agronomía Colombiana, 29(2), 213-220.

Kataria, S., Baghel, L., \& Guruprasad, K. (2015). Acceleration of germination and early growth characteristics of soybean and maize after pre-treatment of sedes with static magnetic field. IJTA, 33(2), 985-992.

Kaune, W. T. (1995). Comments on "Designing EMF experiments: What is required to characterize "exposure"?". Bioelectromagnetics, 16(6), 402-404. https://doi.org/10.1002/bem.2250160608

Lee, M. (1996). Electric and biological effects of transmission lines: A review. Denton, Texas: USDOE Bonneville Power Administration, Portland, OR (USA). 
Maffei, M. (2014). Magnetic field effects on plant growth, development and evolution. Frontiers in plant Science, 5(445), 445-462. https://doi.org/10.3389/fpls.2014.00445

Maguire, J. (1962). Speed of germination-Aid in selection and evaluation for seedling emergence and vigour. Crop Sci., 2, 176-177. https://doi.org/10.2135/cropsci1962.0011183X000200020033x

Majd, A., Shabrangi, A., Bahar, M., \& Abdi, S. (2009). Effect of AC and DC Magnetic Fields on Seed Germination and Early Vegetative Growth in Brassica napus L. Progress in Electromagnetics Research Symposium Proceeding, 18(21), 710-714.

Martínez, E., Carbonell, V., \& Amaya, J. (2000). Static Magnetic Field of $125 \mathrm{mT}$ Stimulates the Initial Growth Stages of Barley (Hordeum vulgare L.). Electro- and Magnetobiology, 19(3), 271-277. https://doi.org/ 10.1081/JBC-100102118

Martínez, E., Carbonell, V., Flórez, M., \& Amaya, J. (2007). Mean Germination Time and Germination Rate of Oat Seeds Subjected to Stationary Magnetic Field. Ingeniería de Recursos Naturales y del Ambiente, 6, 62-66.

Martinez, E., Florez, M., \& Carbonell, M. (2017). Stimulatory Effect of the Magnetic Treatment on the Germination of Cereal Seeds. International Journal of Environment, Agriculture and Biotechnology, 2, 375-381. https://doi.org/10.22161/ijeab/2.1.47

Pietruszewski, S., Muszynski, S., \& Dziwulska, A. (2007). Electromagnetic field and electromagnetic radiation as non-invasive external stimulation for seeds (selected methods and responses. International Agrophysics, $21,95-100$.

Pietruszewski, S., \& Martinez, E. (2015). Magnetic field as a method of improving the quality of sowing material: a review. Int. Agrophysics, 29(1), 377-389. https://doi.org/10.1515/intag-2015-0044

Rácuciu, M. (2011). 50 Hz Frequency Magnetic Field Effects on Mitotic Activity in the Maize Root. Romanian J. Biophys, 21(1), 53-62.

Rácuciu, M., \& Creanga, D. (2006). Static magnetic field influence on some plant growth. Rom. Journ. Phys., $51(1-2), 245-251$.

Ranal, M., \& Santana, D. (2006). How and why to measure the germination process? Rev Bras Bot, $21,1-11$. https://doi.org/10.1590/S0100-84042006000100002

Shine, M., Guruprasad, K., \& Anand, A. (2011). Enhancement of germination, growth and photosynthesis in soybean by pre-treatment of seeds with magnetic field. Bioelectromagnetics, 32(6), 474-84. https://doi.org/ 10.1002/bem.20656

Shine, M., Kataria, S., Guruprasad, K., \& Anand, A. (2017). Enhancement of maize seeds germination by magnetopriming in perspective with reactive oxygen species. J. Agric. Crop Res., 5(4), 66-76.

Socorro, A., \& García, F. (2012). Simulation of magnetic field effect on a seed embryo cell. International Agrophysics, 26, 167-173. https://doi.org/10.2478/v10247-012-0024-8

Teixeira da Silva, J., \& Dobránszki., J. (2015). How do magnetic fields affect plants in vitro? In Vitro Cell. Dev. Biol.-Plant, 51(3), 233-240. https://doi.org/10.1007/s11627-015-9675-z

Torres, J., Hincapie, E., \& Gilart, F. (2018). Characterization of magnetic flux density in passive sources used in magnetic stimulation. Journal of Magnetism and Magnetic Materials, 499(1), 366-371. https://doi.org/ 10.1016/j.jmmm.2017.10.037

Torres, J., Socorro, A., \& Hincapie, E. (2018). Effect of Homogeneous Static Magnetic Treatment on the Adsorption Capacity in Maize Seeds (Zea mays L.). Bioelectromagnetics, 39(5), 343-351. https://doi.org/ 10.1002/bem. 22120

Valberg, P. (1995). Designing EMF experiments: What is required to characterize "exposure"? Bioelectromagnetics, 16, 396-401. https://doi.org/10.1002/bem.2250160608

Van, P., Teixeira da Silva, J., Ham, L., \& Tanaka, M. (2011). Effects of permanent magnetic fields on the proliferation of Phaaenopsis protocorn-like bodies using liquid medium. Scientia Horticulture, 128, 479-484. https://doi.org/10.1016/j.scienta.2011.01.018

Vashisth, A., \& Joshi, D. (2016). Growth Characteristics of Maize Seeds Exposed to Magnetic Field. Bioelectromagnetics, 38(2), 151-157. https://doi.org/10.1002/bem.22023 
Vashisth, A., \& Nagarajan, S. (2008). Exposure of Seed to Static Magnetic Field Enhances Germination and Early Growth Characteristics in Chickpea (Cicer arietinum L.). Biolectromagnetics, 29, 571-578. https://doi.org/10.1002/bem.20426

Vashisth, A., \& Nagarajan, S. (2009). Germination Characteristics of Seeds of Maize (Zea mays L.) Exposed to Magnetic Fields under Accelerated Ageing Condition. Journal of Agricultural Physics, 9, 50-58.

Vashisth, A., \& Nagarajan, S. (2010). Characterization of water distribution and activities of enzymes during germination in magnetically-exposed maize (Zea mays L) seeds. Indian journal of biochemistry \& biophysics, 47, 311-318.

Zepeda, R., Hernandez, C., Dominguez, A., Cruz, A., Godina, J., \& Martínez-Ortíz's, E. (2010). Electromagnetic field and seed vigour of corn hybrids. International Agrophysics, 24, 329-332.

Zepeda, R., Hernandez, C., Suazo, F., Dominguez, A., Cruz, A., Martínez, E., \& Hernández, L. (2011). Physical characteristics of maize grain and tortilla exposed to electromagnetic field. Internaional Agrophysics, 25, 389-393.

Zepeda, R., Hernandez, C., Suazo, F., Dominguez, A., Virgen, J., Perez, C., \& Peón, I. (2014). Electromagnetic field in corn grain production and health. African Journal of Biotechnology, 13(1) 76-83. https://doi.org/ 10.5897/AJB2013.13245

\section{Copyrights}

Copyright for this article is retained by the author(s), with first publication rights granted to the journal.

This is an open-access article distributed under the terms and conditions of the Creative Commons Attribution license (http://creativecommons.org/licenses/by/4.0/). 